\title{
Effect of MgO Content on Mechanical Properties of Directionally Solidified Pure Magnesium
}

\author{
Yuming Chen ${ }^{a}\left(\mathbb{0}\right.$, Zhongxue Feng ${ }^{a, *} \mathbb{1}$, Wanneng Zhang ${ }^{a}$ \\ ${ }^{a}$ Kunming University of Science and Technology,Kunming, School of Materials Science and \\ Engineering, 650093, Yunnan, China.
}

Received: October 10, 2020; Revised: December 1, 2020; Accepted: January 14, 2021

\begin{abstract}
The pure magnesium was fabricated by directional solidification, and the effect of the distribution characteristics of magnesium oxide $(\mathrm{MgO})$ on the mechanical properties of pure magnesium was investigated. The statistical results showed that the area fraction, number and size of $\mathrm{MgO}$ were decreased gradually from the top region ingot to the bottom region ingot, and these reflected the advantages of directional solidification technology in the controllability of $\mathrm{MgO}$ distribution characteristics. The top parts of magnesium ingots have the highest tensile strength (44 MPa), which is mainly due to the presence of a large amount of the coarse $\mathrm{MgO}$. Though the coarse $\mathrm{MgO}$ increases the strength obviously, it has harm for the ductility of magnesium. The top parts of magnesium ingots have higher ultimate tensile strength, but lower failure strain (13\% and $-21 \%$ respectively) than the ingot at the center. These results indicate that if the suitable size and amount of $\mathrm{MgO}$ existed in magnesium matrix, it could avoid the disadvantages of $\mathrm{MgO}$ and provide positive effect for both the strength and ductility of magnesium alloys.
\end{abstract}

\section{Keywords: Magnesium oxide, Directional solidification, Tensile properties, Diffusion mechanism}

\section{Introduction}

Magnesium ( $\mathrm{Mg})$ is the lightest structural metal with rich resources on Earth, and it is the promising engineering material to improve energy efficiency and system performance in the automotive and electronic industry ${ }^{1-6}$. Magnesium alloys consumption has increased to the third most used structural metal only behind iron and aluminum-based alloys $^{7}$. However, since $\mathrm{Mg}$ has low strength and poor plasticity, its applications are greatly limited. In the present, how to improve the ductility and the strength of $\mathrm{Mg}$ at room temperature plays a key role in extending the application of $\mathrm{Mg}$ alloy ${ }^{8}$. Nowadays, the various methods are used to strengthen $\mathrm{Mg}$ alloys, such as alloying, precipitation strengthening and fine-grained strengthening ${ }^{8-11}$. Among them, the precipitation strengthening is one of the most effective methods to improve the mechanical properties of $\mathrm{Mg}$ alloys, because most of the intermetallic compounds (such as $\mathrm{MgZn}_{2}{ }^{12}, \mathrm{MgSn}$ and $\mathrm{Mg}_{12} \mathrm{ZnY}^{13}$ ) can enhance the mechanical properties of $\mathrm{Mg}$ alloys by pinning up dislocations and hindering the basal slip ${ }^{13,14}$.

As an active metal, $\mathrm{Mg}$ could easily form the eutectic compounds (such as $\mathrm{Mg}_{17} \mathrm{Al}_{12}{ }^{15}$ and $\mathrm{Mg}_{2} \mathrm{Si}^{16}$ ) with adding elements. Unfortunately, these compounds always distribute in the grain boundary with net-shape morphology, mismatch with the Mg matrix, and it was harmful to improving the mechanical strength of $\mathrm{Mg}$ alloys ${ }^{17-19}$. Conversely, magnesium oxides are perfect match with $\mathrm{Mg}$ matrix, and it also has uniform distribution characteristics and good thermal stability (melting point $2800{ }^{\circ} \mathrm{C}$ ) ${ }^{20}$, especially $\mathrm{MgO}$ is the most common phase in pure $\mathrm{Mg}$ and $\mathrm{Mg}$ alloys $\mathrm{s}^{7,21,22}$.

*e-mail: fzxue2003@163.com
However, the effect of $\mathrm{MgO}$ on the mechanical properties of $\mathrm{Mg}$ and $\mathrm{Mg}$ alloys are less reported, it can be attributed to the following reasons (i) it's difficult to control the distribution of $\mathrm{MgO}$ (gradient distribution), and the researchers are more interested in grain boundary, grain size and grain orientation $^{23,24}$, and so on; (ii) many researches have been focused on the disadvantage of $\mathrm{MgO}$ on the surface properties of the $\mathrm{Mg}$ alloys ${ }^{25}$. Additionally, it is generally accepted that the oxide $(\mathrm{MgO})$ on the surface has a Pilling-Bedworth ratio $<1$ leading to the porous oxide film of magnesium, which is not as protective as the passive films on $\mathrm{Al}^{21}$. Furthermore, $\mathrm{MgO}$ could easily react with $\mathrm{H}_{2} \mathrm{O}$ in atmospheric conditions forming magnesium hydroxide $\left(\mathrm{Mg}(\mathrm{OH})_{2}\right)$, and it is soluble in environments below $\mathrm{pH}=11$, and many studies focus on the influence of $\mathrm{MgO}$ on the corrosion properties of magnesium alloys s,26,27. $^{\text {. }}$

Directional solidification (DS) is a metallurgical technology that establishes a temperature gradient in a specific direction in the solidified area and the unsolidified area during the solidification of the alloy, which effectively changes the grain orientation and morphology in the solidification structure ${ }^{28,29}$. Therefore, DS can be used to control the distribution of $\mathrm{MgO}$. And there is no relevant research about the $\mathrm{MgO}$ structure and how it can affect the mechanical properties of $\mathrm{Mg}$ alloy. Nevertheless, the study of the distribution characteristic of $\mathrm{MgO}$ and its effect on the mechanical properties of magnesium alloy can help to understand the internal relationship between the distribution characteristic of $\mathrm{MgO}$ and the mechanical properties of $\mathrm{Mg}$ alloys. Most importantly, it's also beneficial to develop the new technology about the recycling and reusing of $\mathrm{Mg}$. 
In order to investigate the effects of the distribution characteristic of $\mathrm{MgO}$ on the mechanical properties of magnesium alloys, this work used the direction solidification method to control the distribution characteristic of $\mathrm{MgO}$ in pure magnesium, and established a relationship between the distribution of $\mathrm{MgO}$ and the mechanical properties of $\mathrm{Mg}$. Among them, pure magnesium is selected as the base alloy, which can greatly avoid the influence of other intermetallic compounds, and the directionally solidified magnesium ingot is coarse columnar grains that grow along the direction of heat flow, so the grain size and grain orientation of different regions are consistent ${ }^{30,31}$, thus ensuring that magnesium oxide is the most important influencing factor.

\section{Experimental Procedure}

\subsection{Preparation of casting specimens}

Samples used in this work were prepared from commercially pure magnesium (Suzhou Haichuan Rare Metal Products Co. Ltd., China) by the directional solidification. The chemical compositions of the raw $\mathrm{Mg}$ were listed in Table 1. The pure $\mathrm{Mg}$ melted in a self-manufactured furnace, which structure was shown in Figure 1, and it was also described in our previous works ${ }^{30}$. The directional solidification process was performed in an inert argon atmosphere to avoid the oxidation of the pure Mg. First, the samples were put into stainless steel crucibles with a $28 / 30 \mathrm{~mm}$ diameter (inside/outside diameter) and a length of $165 \mathrm{~mm}$. Secondly, the specimens were heated to $1003 \mathrm{~K}$ over $1 \mathrm{~h}$ and thermally stabilized for $2 \mathrm{~h}$. When the magnesium is completely melted, turned off the bottom set of resistive wires labeled '(2)' in Figure 1, cooled the bottom of crucibles by a water-cooled copper base, and then controlled the top set of resistive wires labeled '(1)' in
Figure 1, to keep the samples cool with $10{ }^{\circ} \mathrm{C} / \mathrm{min}$. At the end of the experiment, when the temperature went down to $673 \mathrm{~K}$, turned off all the power and remained the sample in the furnace until the temperature went down to room temperature. As shown in Figure 1, the length of the sample was about $130 \mathrm{~mm}$ and the grain size was about $10 \mathrm{~mm}$.

\subsection{Microstructural characterization}

The casting samples were mechanically polished and etched with a $4 \%$ nital, an ethanol solution of picric acid and glacial acetic acid (2.0 g picric acid, $5 \mathrm{ml}$ glacial acetic acid, $5 \mathrm{ml}$ water and $25 \mathrm{ml}$ ethanol). Microstructures of the alloys were observed by optical microscope (OM), scanning electron microscope (SEM) and using a JEOL JSM-6400 microscope equipped with Oxford Link Energy Dispersive $\mathrm{X}$-ray (EDS) microanalysis spectrometer. A microstructural area of $4 \mathrm{~mm}^{2}$ (a quarter of the cross-section) was grabbed from $\mathrm{OM}$ pictures at $200 \times$. The quantitative distribution characteristic of $\mathrm{MgO}$ was statistics by image processing. The details of the quantification procedure of phase were documented elsewhere ${ }^{32-34}$.

\subsection{Calculation details and mechanical property test}

Our calculations were performed using the Cambridge Serial Total Energy Package Code (CASTEP) based on density functional theory (DFT). The Generalized Gradient Approximation (GGA) was employed to evaluate exchangecorrelation energy. Ultra-soft pseudo-potentials were used for electron-ion interactions and the electron wave function was expanded using plane waves. $2 \mathrm{p}^{6} 3 \mathrm{~s}^{2}$ of $\mathrm{Mg}$ and $2 \mathrm{~s}^{2} 2 \mathrm{p}^{4}$ of $\mathrm{O}$ are treated as valence electrons were involved in the calculations. The cut-off energy is $380 \mathrm{eV}$ and the K-point of $\mathrm{MgO}$ is $12 \times 12 \times 12$ and that of $\mathrm{Mg}$ is $18 \times 18 \times 12$ to

Table 1. Chemical composition of Pure Magnesium. (wt. \%)

\begin{tabular}{cccccccccc}
\hline Alloy & $\mathrm{Al}$ & $\mathrm{Mn}$ & $\mathrm{Cu}$ & $\mathrm{Fe}$ & $\mathrm{Ni}$ & $\mathrm{Mg}$ & \\
\hline Pure Mg & 0.025 & 0.016 & 0.004 & 0.0032 & 0.0005 & 0.017 & $\mathrm{Remain}$ \\
\hline
\end{tabular}
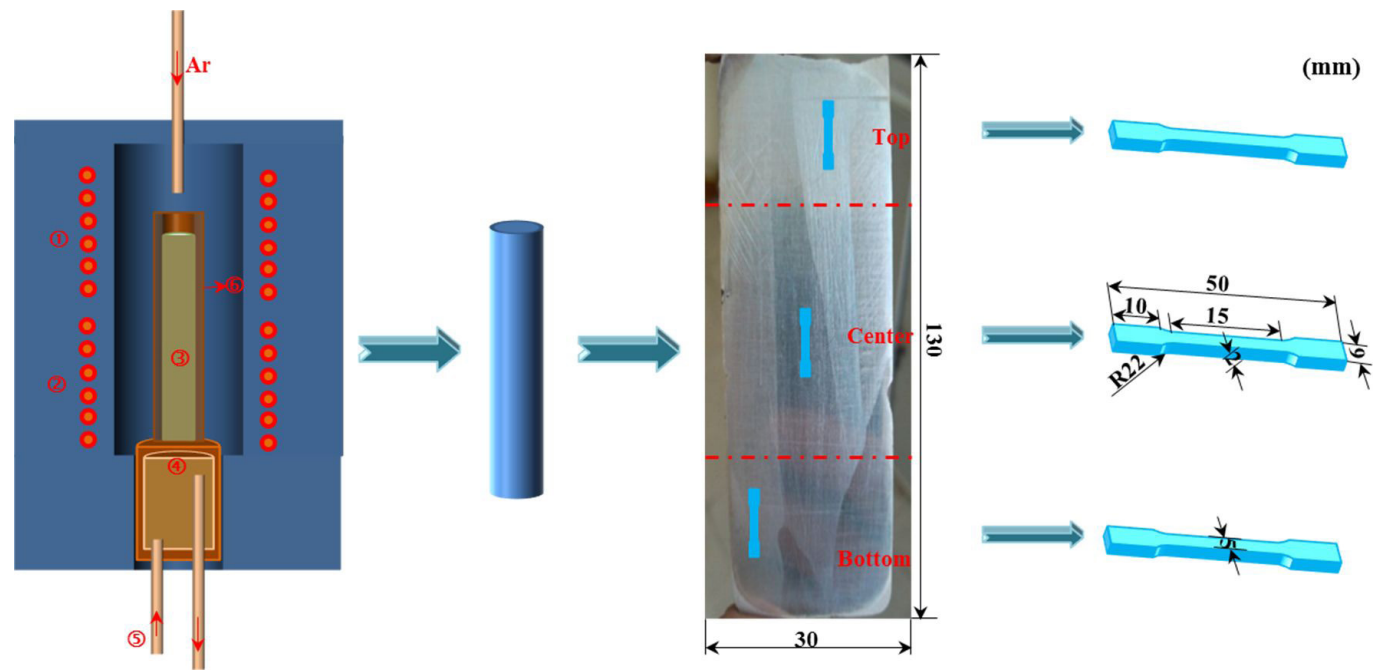

Figure 1. Schematic of the experimental set-up and the position and dimension of tensile specimens: (1)- the top set of resistive wires, (2)- the bottom set of resistive wires, (3)- magnesium melt, (4)- water-cooled copper base, (5)- cooling water, (6)- stainless steel crucible 
ensure the convergence of the system energy and configuration at the plane wave group level. The Vickers hardness (HV) of the samples was measured with a micro-hardness tester (AHVD-1000XY, Jvjing) at room temperature using a load of $100 \mathrm{~g}$ for $15 \mathrm{~s}$. Each sample continuously selected 10 hardness test points along the horizontal direction of the sample, the distance between each two test points is $0.6 \mathrm{~mm}$, and the average hardness values were adopted as the results. In order to obtain the effect of position on mechanical properties of $\mathrm{Mg}$, the tensile specimens of a cross section of $2 \mathrm{~mm} \times 5 \mathrm{~mm}$ and $15 \mathrm{~mm}$ gauge length were machined from the bottom, center and top of the ingot, as shown in Figure 1. Uniaxial tensile test was performed on the bottom, center and top specimens at a constant strain rate of $10^{-4} / \mathrm{s}$ in a computer controlling servo-hydraulic test machine at room temperature. At the end of the test, the fracture surface was observed by the SEM.

\section{Results and Discussion}

\subsection{Distribution characters of $\mathrm{MgO}$}

Figure 2 showed the microstructures of the top, the center and the bottom regions of the pure magnesium ingot respectively, and it mainly consisted of well-development primary $\alpha-\mathrm{Mg}$ and $\mathrm{MgO}$. It should be noticed that the differences in the size, the amount and the morphology of $\mathrm{MgO}$ were observed among the three regions of the ingot. The size difference among $\mathrm{MgO}$ in the top region of ingot was bigger than the $\mathrm{MgO}$ in the other two regions, and the coarser
$\mathrm{MgO}$ was mainly occurred at the top of ingot. As shown in Figure 2(d-f), there are not only $\mathrm{MgO}$ particles in the matrix, but also other impurity phases, and the element composition is shown in Table 2. In addition, a variety of elements were found in the impurity phase in the bottom region, among which the presence of Fe element had a passive impact on the mechanical properties of the magnesium matrix ${ }^{30}$. In order to investigate the size difference and the distribution characteristic of $\mathrm{MgO}$ in casting, we counted the number density and the area fraction of $\mathrm{MgO}$ in the top, the center and the bottom region of casting, as shown in Figure 3. In the top region of ingot, when the size of $\mathrm{MgO}$ is less than $100 \mu \mathrm{m}$, the area fraction of $\mathrm{MgO}$ is maintained at a low value. But the area fraction of $\mathrm{MgO}$ increased sharply to $0.62 \%$ with the size of $\mathrm{MgO}$ larger than $100 \mu \mathrm{m}$. The area fraction is three times than other sizes of $\mathrm{MgO}$. Additionally, the number density of $\mathrm{MgO}$ reduced sharply with the size of $\mathrm{MgO}$ increasing, high proportion of the number density of $\mathrm{MgO}$ (around $82 \%$ ) belongs to $0-25 \mu \mathrm{m}$. This tendency was observed in both the center and bottom regions of ingot. In the center region of ingot, the area fraction of $\mathrm{MgO}$ displayed the same tendency as the top region, and the area fraction of $\mathrm{MgO}$ in the center region of ingot was larger than the top ingot (its size was in 0-25 $\mu \mathrm{m}$, and 25-50 $\mu \mathrm{m}$ ). The area fraction of $\mathrm{MgO}$ with the size larger than $100 \mu \mathrm{m}$ was $0.58 \%$, and it's less than the area fraction of $\mathrm{MgO}$ in the top ingot. These data implied that the total area fraction of $\mathrm{MgO}$ and amount of coarser $\mathrm{MgO}$ reduced from top to center of ingot gradually. In the bottom of ingot, the area fraction of $\mathrm{MgO}$

Table 2. The EDS data of the marked point in Figure 2. (wt. \%)

\begin{tabular}{cccccc}
\hline Point & $\mathrm{Mg}$ & $\mathrm{O}$ & $\mathrm{Si}$ & $\mathrm{Al}$ & $-\mathrm{Fe}$ \\
\hline Point 1 & 95.15 & 4.85 & - & - & - \\
\hline Point 2 & 64.99 & 3.55 & 31.46 & - & - \\
\hline Point 3 & 72.55 & 27.45 & - & - & - \\
\hline Point 4 & 57.35 & 3.48 & 33.78 & 0.94 \\
\hline
\end{tabular}
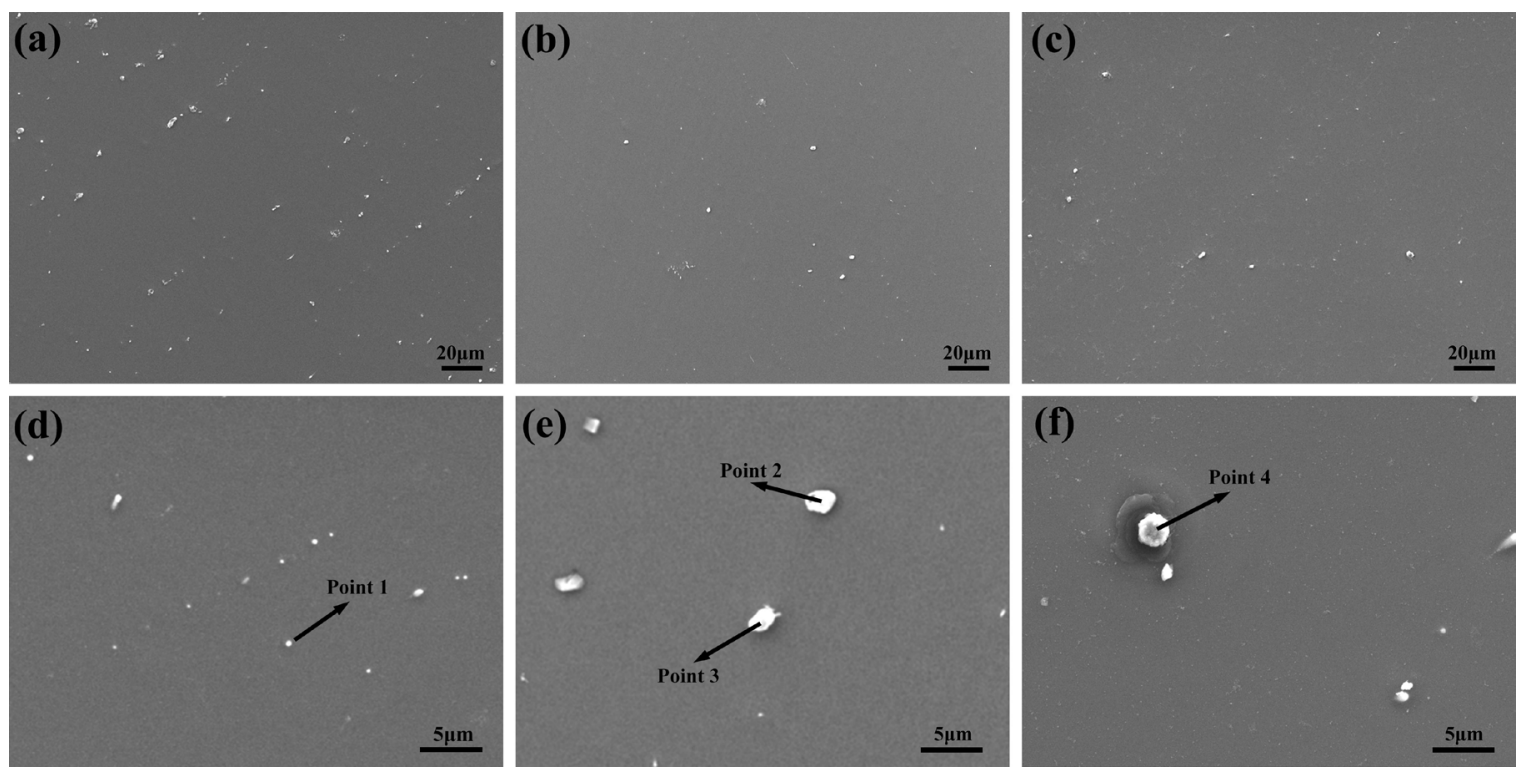

Figure 2. The morphology of the different regions of the casting: (a) (d) top; (b) (e) center; (c) (f) bottom 

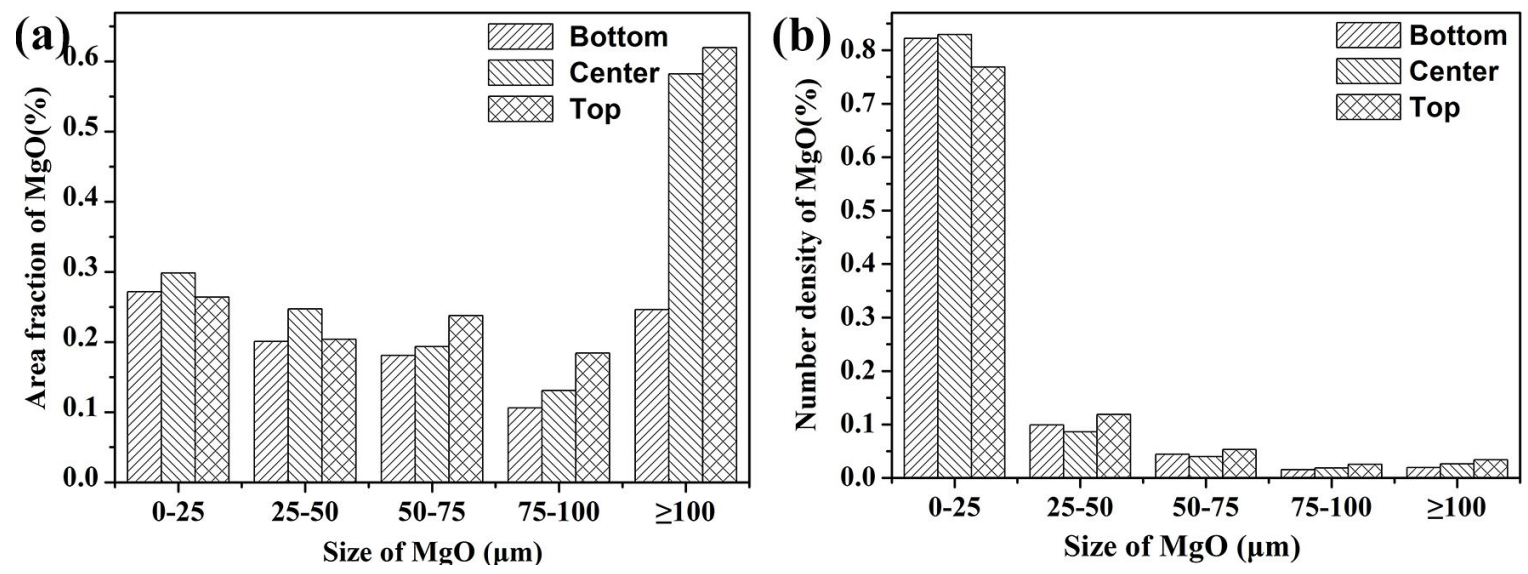

Figure 3. The area fraction and the number density of the $\mathrm{MgO}$ in the different size range: (a) the area fraction of the impurity phases in the different size range; (b) the number density of the $\mathrm{MgO}$ in the different size range

with the size larger than $100 \mu \mathrm{m}$ was only $0.25 \%$, and it was lower than the top and center region ingot. The total area fraction of $\mathrm{MgO}$ from the top to the bottom ingot was $1.51 \%$, $1.45 \%$ and $1.01 \%$, respectively. These data indicated that the area fraction, number and size of $\mathrm{MgO}$ reduced from the top to the bottom of ingot. The coarser $\mathrm{MgO}$ mainly appeared in the top region of ingot and the bottom region's impurity phase size was relatively small and uniform.

The reason for the distribution of $\mathrm{MgO}$ was considered to be related to the diffusion behavior of oxygen in the magnesium melt. During the melting process, the oxygen diffused into the magnesium melt surface through the protective gas (Argon) layer. The diffusion coefficient of oxygen in the protective gas layer could be obtained according to the Fuller-Schettler and Giddings correlation, as shown in Equation 1.

$$
D=\frac{4.357 \times 10^{-2} T^{3 / 2}\left[\left(1 / M_{A}\right)+\left(1 / M_{B}\right)\right]^{1 / 2}}{P\left[\left(V_{A}\right)^{1 / 3}+\left(V_{B}\right)^{1 / 3}\right]^{2}}
$$

Where $T$ is the temperature of the gas; $M_{A}$ and $M_{B}$ are the molar mass of $\mathrm{A}$ and $\mathrm{B}, \mathrm{M}_{\mathrm{O} 2}=0.032 \mathrm{~kg} / \mathrm{mol}, \mathrm{M}_{\mathrm{Ar}}=0.04 \mathrm{~kg} /$ mol; $\mathrm{P}$ is the pressure of gas, $\mathrm{P}=1 \times 10^{5} \mathrm{~Pa} ; \mathrm{V}_{\mathrm{A}}$ and $\mathrm{V}_{\mathrm{B}}$ represent the liquid molecular volume in the normal boiling point of gas $\mathrm{A}$ and $\mathrm{B}, \mathrm{V}_{\mathrm{O} 2}=2.56 \times 10^{-7} \mathrm{~m}^{3} / \mathrm{mol}, \mathrm{V}_{\mathrm{Ar}}=2.86 \times 10^{-7} \mathrm{~m}^{3} / \mathrm{mol}$. When $\mathrm{T}=1003 \mathrm{~K}$, we could solve $\mathrm{D}=620 \mathrm{~m}^{2} / \mathrm{s}$. According to the Fick's first law, when D is constant, the diffusion speed is determined by the absorption speed of oxygen of magnesium melt. There were two forms of oxygen existing in magnesium melt, solid solution and compound. Because the magnesium was prone to react with oxygen, and $\mathrm{MgO}$ was the mainly phase of oxygen in the magnesium melt. The Gibbs free energy of the reaction between magnesium and oxygen could be determined by Equation 2 .

$$
\begin{aligned}
& M g(L)+\frac{1}{2} O_{2}(g)=M g O(S) \quad \Delta \mathrm{G}_{\mathrm{Mg} 0}=-669350+135.0 \mathrm{~T} \quad(\mathrm{~J} / \mathrm{mol}) \\
& \frac{1}{2} O_{2}=[O] \quad \Delta \mathrm{G}_{I}=500000-90 \mathrm{~T} \quad(\mathrm{~J} / \mathrm{mol})
\end{aligned}
$$

$$
\begin{aligned}
& \Delta \mathrm{G}_{I I I}=-R T \ln K=-R T \ln \frac{M g O}{[M g][O]}=\Delta G_{M g O}+\Delta G_{I} \\
& \lg \{[O]\}=2.353-8856 / T
\end{aligned}
$$

Where $[\mathrm{Mg}]$ and $[\mathrm{O}]$ is the density of magnesium and oxygen atomic, the critical value of the oxygen density of reaction can be obtained from equation (5). When $\mathrm{K}=1003 \mathrm{~K}$, [O] was equal to $3.34 \times 10^{-7}$. Since the critical value of the oxygen density was very low during the oxygen and magnesium reaction, the oxygen mainly existed as $\mathrm{MgO}$ and there were only very low levels of residual free oxygen existing in the magnesium melt. During the melting of the pure magnesium, the residuary air in the furnace diffused into the magnesium matrix and form a compact layer on the surface, as shown in Figure 4(a). However, as shown in Figure 4(b), with the holding time increasing, since the volume difference between compact layer and metallic matrix and the transport of $\mathrm{Mg}$ vapor, the internal stress would arise and lead the compact layer break ${ }^{20,21}$. Many cracks occurred in the compact layer at this time. The cracks could provide easy paths for oxygen diffusion to the magnesium melt. And during the breaking process, many different sizes of $\mathrm{MgO}$ were escaped from the loose compact layer and appeared below the compact layer. In these $\mathrm{MgO}$, the coarser $\mathrm{MgO}$ would float on the surface of magnesium melt, and the other fine dense $\mathrm{MgO}$ slowly moved toward the bottom of the crucible. And these fine $\mathrm{MgO}$ would grow up by swallowing other free $\mathrm{MgO}$ in the magnesium melt during the subsided processing. Therefore, the coarser $\mathrm{MgO}$ was mainly occurred at the top region of ingot. The area fraction, number and size of $\mathrm{MgO}$ in the top region of the ingot were larger than both the center and bottom ingot. This is why the $\mathrm{MgO}$ has a gradient distribution characteristic in the ingot.

\subsection{Effect of $\mathrm{MgO}$ on mechanical properties}

The mechanical property of $\mathrm{MgO}$ plays an important role in the reposed behaviors of magnesium and magnesium alloy during deformation process. Therefore, it was essential to investigate the elastic stiffness of $\mathrm{MgO}$. The quotient between shear modulus $(G)$ and bulk modulus $(K) \mathrm{G} / \mathrm{K}$ can 


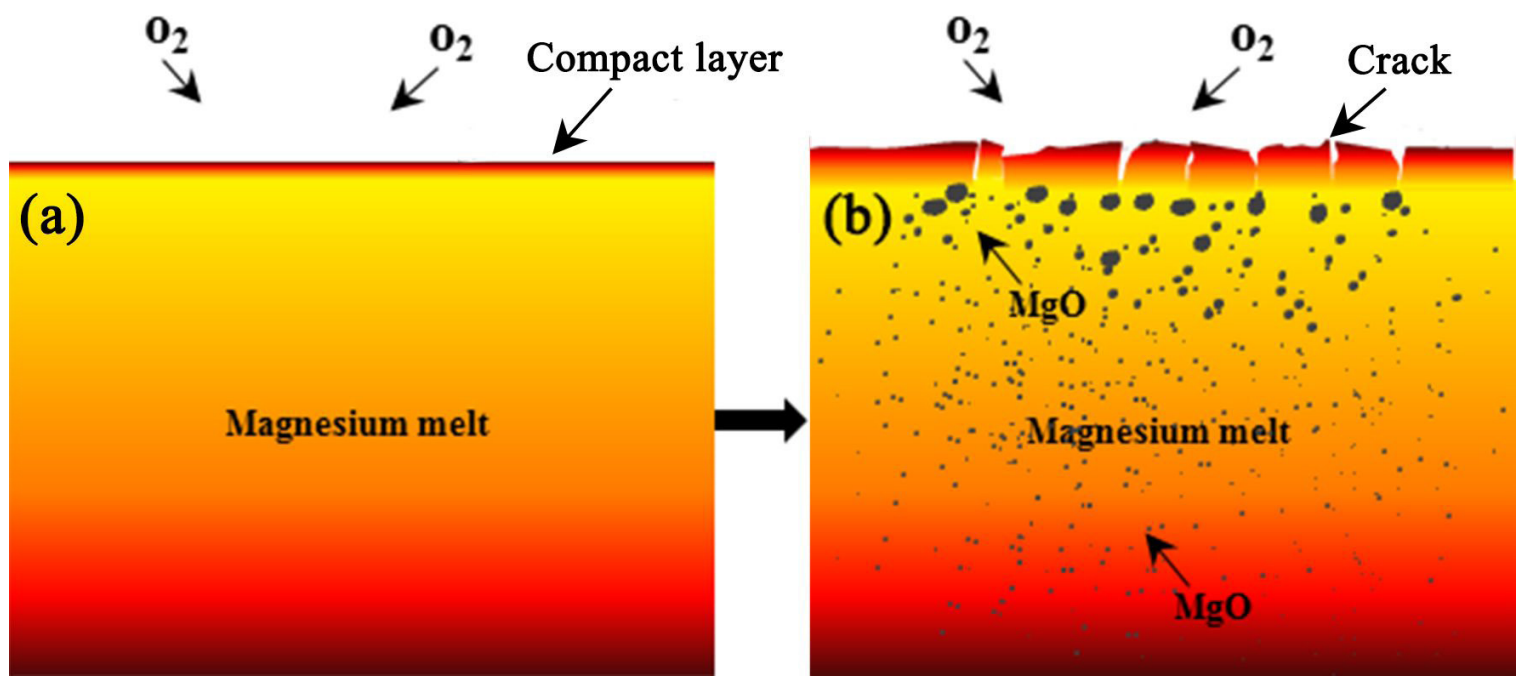

Figure 4. Schematic of the stages for $\mathrm{MgO}$ growth on the surface of magnesium melt: (a) the initial state of magnesium melt; (b) distribution of different size of $\mathrm{MgO}$ in magnesium melt

Table 3. Voigt (index $V$ ), Reuss (index $R$ ), and averaged macroscopic modulus for the $\mathrm{Mg}$ and $\mathrm{MgO}$ phase; all in Gpa except for $v$ (dimensionless)

\begin{tabular}{crrrrrrrrrr}
\hline Phase & $\mathrm{K}_{\mathrm{V}}$ & $\mathrm{K}_{\mathrm{R}}$ & $\mathrm{K}$ & $\mathrm{G}_{\mathrm{V}}$ & $\mathrm{G}_{\mathrm{R}}$ & $\mathrm{G}$ & $\mathrm{E}$ & $v$ & $\mathrm{G} / \mathrm{K}$ & $\mathrm{A}_{\mathrm{G}}$ \\
\hline $\mathrm{Mg}$ & 35.1 & 35.1 & 35.1 & 16.3 & 14.7 & 15.5 & 40.5 & 0.308 & 0.442 & $5.2 \%$ \\
\hline $\mathrm{MgO}$ & 143.7 & 143.7 & 143.7 & 114.0 & 108.7 & 111.4 & 265.3 & 0.192 & 0.775 & $2.3 \%$ \\
\hline
\end{tabular}

be considered as an indication of the extent of fraction range in metals. A low value and a high value of $\mathrm{G} / \mathrm{K}$ are associated with ductility and brittleness, respectively.

The Young's modulus $(E)$, Poisson's ratio $(v)$ and anisotropy parameter $\left(\mathrm{A}_{\mathrm{G}}\right)$ of $\mathrm{Mg}$ and $\mathrm{MgO}$ can be calculated and obtained by relevant formulas in the $\mathrm{Wei}^{39}$, as shown in Table 3 . The $\mathrm{G} / \mathrm{K}$ values were 0.442 and 0.775 for the $\mathrm{Mg}$ and $\mathrm{MgO}$ phase, respectively. As we know, the material was regarded as brittle if the value of $\mathrm{G} / \mathrm{K}$ was more than 0.57 . This suggested that $\mathrm{MgO}$ has brittleness. According to calculations, the bulk modulus of $\mathrm{Mg}$ (40.5 GPa) was much smaller than that of $\mathrm{MgO}(265.3 \mathrm{GPa})$, and $\mathrm{MgO}$ had larger shear modulus (111.4 GPa). These results implied that the shape of $\mathrm{MgO}$ was difficult to change or broken to small pieces during the deformation process and it had a strengthening effect on the magnesium matrix. Additionally, it was known that the elastic anisotropy could be measured using dimensionless quantity $\mathrm{A}_{\mathrm{G}}$. The results demonstrated that the $\mathrm{Mg}$ was more anisotropic than $\mathrm{MgO}$, and it also agreed with the following calculation results of anisotropy. To investigate the elastic modulus anisotropy of $\mathrm{MgO}$ and $\mathrm{Mg}$, a three-dimensional surface representation of elastic anisotropy was employed to show the variation of the elastic modulus with the crystallographic direction, and these results were shown in Figure 5. Since the shape of the three-dimensional surface would indicate the degree of anisotropy of phases, for example the spherical shape indicated the isotropic phase. From the three-dimensional surface images, it could be found that the $\mathrm{Mg}$ was much more anisotropic than $\mathrm{MgO}$, since the shape of the three- dimensional surface image of $\mathrm{MgO}$ tends to spherical shape and the shape of $\mathrm{Mg}$ was fusiform shape.

Figure 6 showed the microhardness and stress-strain curves of the different regions of the casting. The mechanical properties were provided in Table 4 . It can be seen from the microhardness of the three areas of the ingot that the microhardness of the top ingot is the largest $(58.8 \pm 3.5 \mathrm{HV})$, which was related to the content and size of the $\mathrm{MgO}$ particles. However, the content of $\mathrm{MgO}$ particles in the bottom ingot was the least, and the microhardness was greater than that in the center ingot. This was mainly due to the large amount of impurity phases in the bottom ingot, and these impurity phases include $\mathrm{MgO}$ and mixtures (including $\mathrm{Al}, \mathrm{Fe}$ and $\mathrm{Si})^{40}$. Figure $6 \mathrm{~b}$ was a typical strain strengthening curve. The stress increased gradually to the peak and then decreased drastically. It should be mentioned that in the center ingot, the elongation of sample (61\%) was much higher than the bottom ingot $(30 \%)$, although the area fraction and the size of $\mathrm{MgO}$ in bottom was smaller than that of the center. The other interesting finding was that the top region with a high area fraction of $\mathrm{MgO}$ showed high yield strength $(9 \mathrm{MPa})$ and tensile strength (44 MPa). Combined with the above statistical results of $\mathrm{MgO}$, it suggested that the magnesium matrix with finer $\mathrm{MgO}(<50 \mu \mathrm{m})$ had better plasticity than those with coarser $\mathrm{MgO}(>100 \mu \mathrm{m})$. But the coarser $\mathrm{MgO}$ increased strength much more significantly than those with finer $\mathrm{MgO}$.

Figure 7 showed the fracture surfaces of tensile samples in the different regions of the casting alloy. All samples exhibited a fracture surface with cleavage facets and deep tearing ridges. These features showed evidence that the cross slipping and twinning played an important role 
(a)

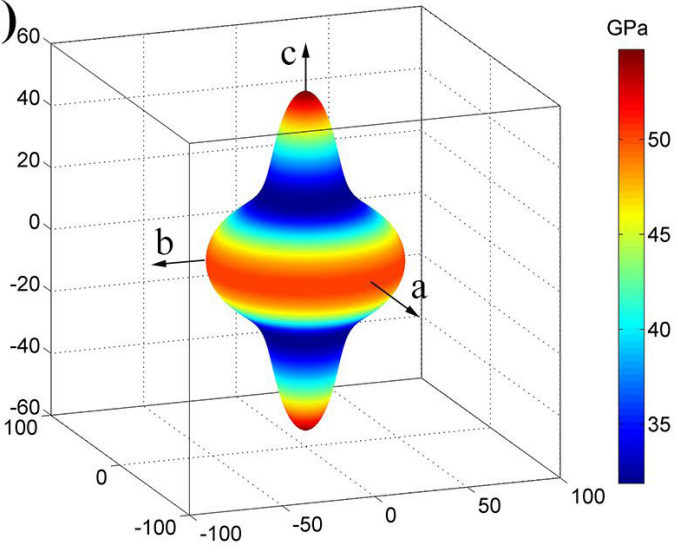

(b)

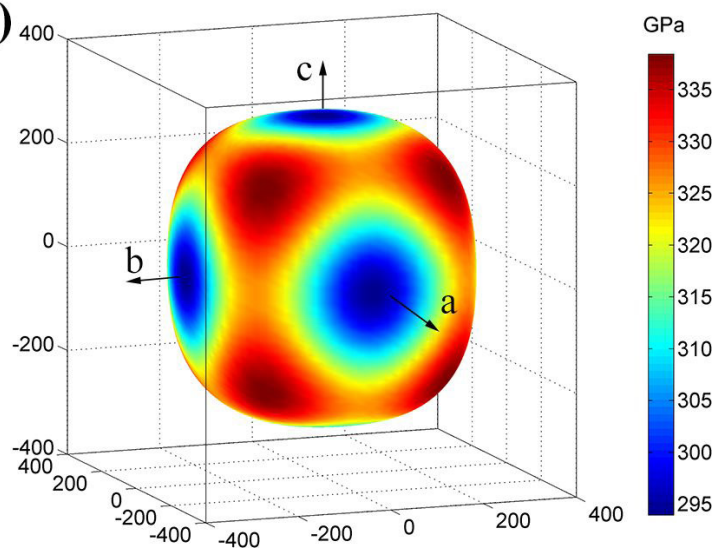

Figure 5 .Three-dimensional diagrams of the Young's modulus of $\mathrm{Mg}$ and $\mathrm{MgO}$ phase: (a) $\mathrm{Mg}$; (b) $\mathrm{MgO}$
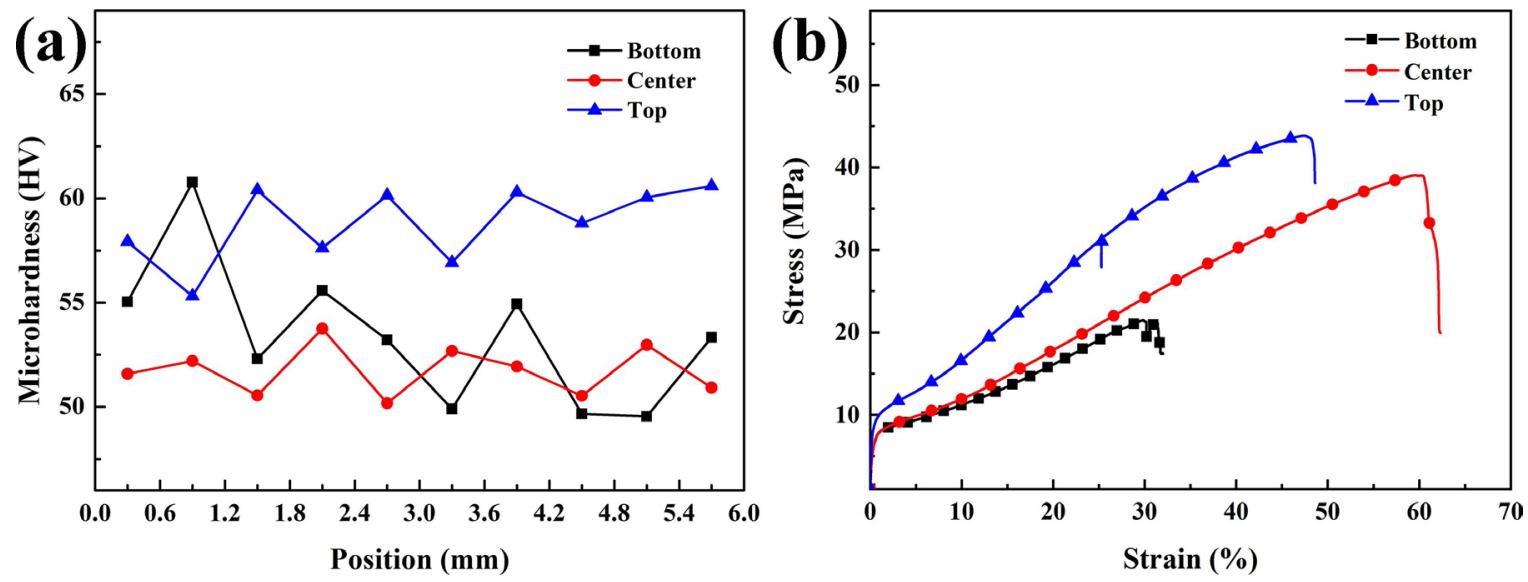

Figure 6. (a) Microhardness and (b) Room temperature tensile stress-strain curves of the different regions of the casting

Table 4. Mechanical properties of different regions of directionally solidified pure magnesium

\begin{tabular}{ccccc}
\hline Regions & Microhardness(HV) & Yield strength (MPa) & Tensile strength (MPa) & Elongation (\%) \\
\hline Bottom & $53.4 \pm 7.4$ & $7 \pm 2$ & $21 \pm 2$ & $30 \pm 0.2$ \\
\hline Center & $51.7 \pm 2$ & $7 \pm 1$ & $39 \pm 3$ & $61 \pm 0.3$ \\
\hline Top & $58.8 \pm 3.5$ & $9 \pm 1$ & $44 \pm 3$ & $48 \pm 0.5$ \\
\hline
\end{tabular}

in the process of pure magnesium deformation at room temperature. In the top ingot, as shown in Figure $7 \mathrm{a}$, the fracture surface contained substantial tearing ridges and a few cleavage facets. In comparison, as shown in Figure $7 \mathrm{~b}$, the amount of tearing ridges was much more than the top region, and the area of the cleavage facets on the fracture surface tend to decrease compared to the top region. As shown in Figure 7d, the small porosities were found on the tearing ridges. The formation of the porosity should be related to the finer $\mathrm{MgO}$, which hindered the propagation of tearing ridges. And the tearing ridges were much shorter and more uniform than the top region. In contrast, as shown in Figure 7c, the bottom sample exhibited large cleavage facets, which was much flatter and broader than the other regions. This might be attributed to the brittle element, such as $\mathrm{Fe}, \mathrm{Si}$, and $\mathrm{Al}$, which was segregated to the bottom of ingot during the directional solidification process. These impurity elements would change the interatomic force and alter the slipping mode.

From what had been discussed above, we might finally draw the conclusion that $\mathrm{MgO}$ had some positive effects on the mechanical behavior of magnesium alloys, and the finer $\mathrm{MgO}$ could enhance the strength of the magnesium with good plasticity as well. The $\mathrm{MgO}$ was not only smaller mismatch with the magnesium matrix, but also uniformly distributed in the whole grain, rather than segregation at the grain boundary which was often occurring in the other magnesium alloys. If we could avoid the harmful characteristics of $\mathrm{MgO}$, it could become an important strengthening phase in magnesium and magnesium alloys. 

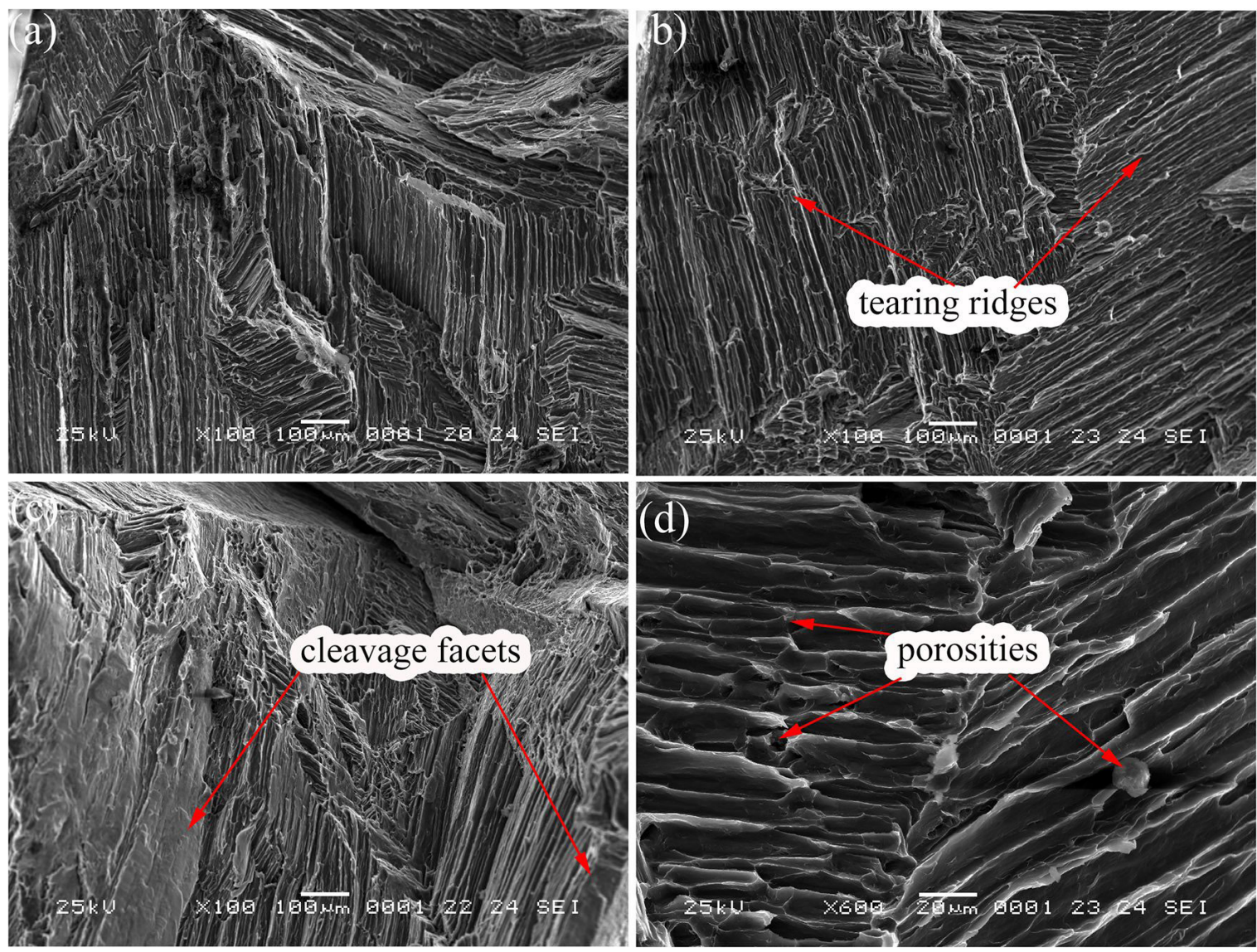

Figure 7. SEM micrographs of fractured tensile samples in the different regions of the casting: (a) top; (b) center; (c) bottom; (d) zoom in of image (b).

\section{Conclusions}

In this work, the effect of microstructures $(\mathrm{MgO}$ particle distribution) and mechanical properties of the different areas of the directionally solidified pure magnesium ingot were studied. The main conclusions are as follows.

1. The distribution characteristics of $\mathrm{MgO}$ in the ingot were related to the diffusion behavior of oxygen closely. Many different sizes of $\mathrm{MgO}$ were formed because the residuary air in the furnace diffuses into the magnesium melt. The finer and denser $\mathrm{MgO}$ slowly moved toward the bottom of the crucible and the coarser $\mathrm{MgO}$ would float on the surface of magnesium melt. Therefore, the area fraction, amount and size of $\mathrm{MgO}$ in the top ingot were larger than the middle and bottom ingot.

2. The coarser $\mathrm{MgO}$ particles $(>100 \mu \mathrm{m})$ could enhance the microhardness and tensile strength of the magnesium matrix, and the finer $\mathrm{MgO}$ particles $(<50 \mu \mathrm{m})$ could improve its plasticity, comparing the mechanical properties of the magnesium ingot at the top and the center.

3. The poor mechanical properties of the bottom ingot are mainly due to the small size and amount of $\mathrm{MgO}$ in the bottom ingot, and the presence of mixed impurities (including $\mathrm{Al}, \mathrm{Fe}$ and other elements).

\section{Acknowledgements}

This work was supported by the Yunnan Province Science Youth Experts Fund [2016FD033], and the Yunnan Provincial Department of Education Fund [201901T070160].

\section{References}

1. Joost WJ, Krajewski PE. Towards magnesium alloys for highvolume automotive applications. Scr Mater. 2017;128:107-12.

2. Li N, Zheng Y. Novel magnesium alloys developed for biomedical application: a review. J Mater Sci Technol. 2013;29(6):489-502.

3. Song J, She J, Chen D, Pan F. Latest research advances on magnesium and magnesium alloys worldwide. Journal of Magnesium and Alloys. 2020;8(1):1-41.

4. Esmaily M, Svensson JE, Fajardo S, Birbilis N, Frankel GS, Virtanen S, et al. Fundamentals and advances in magnesium alloy corrosion. Prog Mater Sci. 2017;89:92-193.

5. Radha R, Sreekanth D. Insight of magnesium alloys and composites for orthopedic implant applications - A review. Journal of Magnesium and Alloys. 2017;5(3):286-312.

6. Wang XJ, Xu DK, Wu RZ, Chen XB, Peng QM, Jin L, et al. What is going on in magnesium alloys? J Mater Sci Technol. 2018;34(2):245-7.

7. Samaniego A, Gusieva K, Llorente I, Feliu S, Birbilis N. Exploring the possibility of protective surface oxides upon $\mathrm{Mg}$ alloy AZ31 via lutetium additions. Corros Sci. 2014;89:101-10.

8. You S, Huang Y, Kainer KU, Hort N. Recent research and developments on wrought magnesium alloys. Journal of Magnesium and Alloys. 2017;5(3):239-53. 
9. Robson JD, Paa-Rai C. The interaction of grain refinement and ageing in magnesium-zinc-zirconium (ZK) alloys. Acta Mater. 2015;95:10-9.

10. Pan H, Ren Y, Fu H, Zhao H, Wang L, Meng X, et al. Recent developments in rare-earth free wrought magnesium alloys having high strength: A review. J Alloys Compd. 2016;663:321-31.

11. Wang F, Bhattacharyya JJ, Agnew SR. Effect of precipitate shape and orientation on Orowan strengthening of non-basal slip modes in hexagonal crystals, application to magnesium alloys. Mater Sci Eng A. 2016;666:114-22.

12. Chen X, Ning F, Hou J, Le Q, Tang Y. Dual-frequency ultrasonic treatment on microstructure and mechanical properties of ZK60 magnesium alloy. Ultrason Sonochem. 2018;40:433-41.

13. Medina J, Pérez P, Garcés G, Adeva P. Effects of calcium, manganese and cerium-rich mischmetal additions on the mechanical properties of extruded $\mathrm{Mg}-\mathrm{Zn}-\mathrm{Y}$ alloy reinforced by quasicrystalline I-phase. Mater Charact. 2017;129:195-206.

14. Liu Y, Ren H, Hu W-C, Li D-J, Zeng X-Q, Wang K-G, et al. First-principles Calculations of Strengthening Compounds in Magnesium Alloy: A General Review. J Mater Sci Technol. 2016;32(12):1222-31

15. Cubides Y, Ivan Karayan A, Vaughan MW, Karaman I, Castaneda $\mathrm{H}$. Enhanced mechanical properties and corrosion resistance of a fine-grained $\mathrm{Mg}-9 \mathrm{Al}-1 \mathrm{Zn}$ alloy: the role of bimodal grain structure and $\beta-M g 17$ Al12 precipitates. Materialia. 2020;13:100840.

16. Seth PP, Singh N, Singh M, Prakash O, Kumar D. Formation of fine $\mathrm{Mg} 2 \mathrm{Si}$ phase in $\mathrm{Mg}-\mathrm{Si}$ alloy via solid-state sintering using high energy ball milling. J Alloys Compd. 2020;821:153205.

17. Chang Shin H, Son J, Min BK, Choi YS, Cho KM, Cho DH, et al. The effect of $\mathrm{Ce}$ on the modification of Mg2Si phases of as-cast eutectic Mg-Si alloys. J Alloys Compd. 2019;792:59-68.

18. Liu J, Zhang L, Liu S, Han Z, Dong Z. Effect of Si content on microstructure and compressive properties of open-cell $\mathrm{Mg}$ composite foams reinforced by in-situ Mg2Si compounds. Mater Charact. 2020;159:110045.

19. Shang S-j, Deng K-k, Nie K-b, Li J-c, Zhou S-s, Xu F-j, et al. Microstructure and mechanical properties of $\mathrm{SiCp} / \mathrm{Mg}-\mathrm{Al}-\mathrm{Zn}$ composites containing Mg17Al12 phases processed by lowspeed extrusion. Mater Sci Eng A. 2014;610:243-9.

20. Xu BS, Li MZ. Magnesium smelting and magnesium alloy smelting process. Bejing: Chemical Industry Press; 2006.

21. Tan Q, Atrens A, Mo N, Zhang M-X. Oxidation of magnesium alloys at elevated temperatures in air: A review. Corros Sci. 2016;112:734-59.

22. Ma S, Xing F, Ta N, Zhang L. Kinetic modeling of hightemperature oxidation of pure Mg. Journal of Magnesium and Alloys. 2020;8(3):819-31.

23. Zhang W-n, Wang L-z, Feng Z-x, Chen Y-m. Research progress on selective laser melting (SLM) of magnesium alloys: A review. Optik (Stuttg). 2020;207:163842.
24. Mo N, Tan Q, Bermingham M, Huang Y, Dieringa H, Hort $\mathrm{N}$, et al. Current development of creep-resistant magnesium cast alloys: A review. Mater Des. 2018;155:422-42.

25. Zheng T, Hu Y, Yang S. Effect of grain size on the electrochemical behavior of pure magnesium anode. Journal of Magnesium and Alloys. 2017;5(4):404-11.

26. Cao F, Song G-L, Atrens A. Corrosion and passivation of magnesium alloys. Corros Sci. 2016;111:835-45.

27. Xu Z, Eduok U, Szpunar J. Effect of annealing temperature on the corrosion resistance of $\mathrm{MgO}$ coatings on $\mathrm{Mg}$ alloy. Surf Coat Tech. 2019;357:691-7.

28. Jia H, Feng X, Yang Y. The mechanical anisotropy of directionally solidified Mg-4 wt.\% Zn alloy under compression test. Mater Sci Eng A. 2019;762:138104.

29. Luo S, Yang G, Liu S, Wang J, Li J, Jie W. Microstructure evolution and mechanical properties of directionally solidified $\mathrm{Mg}-\mathrm{xGd}$ $(\mathrm{x}=0.8,1.5$, and 2.5) alloys. Mater Sci Eng A. 2016;662:241-50.

30. Li FB, Feng ZX, Cao Y, Shi QN. Research of impurity phase in single crystal pure magnesium prepared by directional solidification. Special Casting \& Nonferrous Alloys. 2015;35:208-11.

31. Lu X. Microstructure and mechanical properties in directionally solidified pure magnesium grains with large-diameter. Foundry. 2015;64:1214-7.

32. Pan F, Feng Z, Zhang X, Tang A. The types and distribution characterization of Al-Mn Phases in the AZ61 Magnesium Alloy. Procedia Eng. 2012;27:833-9.

33. Prakash DGL, Regener D. Quantitative characterization of Mg17Al12 phase and grain size in HPDC AZ91 magnesium alloy. J Alloys Compd. 2008;461(1):139-46.

34. Leo Prakash DG, Regener D, Vorster WJJ. Effect of position on the tensile properties in high-pressure die cast $\mathrm{Mg}$ alloy. $\mathrm{J}$ Alloys Compd. 2009;470(1):111-6.

35. Yong QL. The second phase in the steel material. Beijing: Metallurgical Industry Press; 2006.

36. Fujii K, Nagasaka T, Hino M. Activities of the constituents in spinel solid solution and free energies of formation of $\mathrm{MgO}$, $\mathrm{MgO} \cdot \mathrm{A} 12 \mathrm{O} 3$. Transactions of the Iron \& Steel Institute of Japan. 2000;40(11):1059-66.

37. Hallstedt B. The Magnesium: oxygen system. Calphad. 1993;17(3):281-6.

38. Xu ZY. Thermodynamics of metal materials. Beijing: Science Press; 1983.

39. Zhou W, Liu L, Li B, Wu P, Song Q. Structural, elastic and electronic properties of intermetallics in the Pt-Sn system: A density functional investigation. Comput Mater Sci. 2009;46(4):921-31.

40. Cao H, Huang M, Wang C, Long S, Zha J, You G. Research status and prospects of melt refining and purification technology of magnesium alloys. Journal of Magnesium and Alloys. 2019; 7(3):370-80 